\title{
Rajiv PRABHAKAR, Stakeholding and New Labour
}

Basingstoke: Palgrave Macmillan, 2003

\section{Emmanuelle Avril}

\section{(2) OpenEdition}

Journals

Édition électronique

URL : http://journals.openedition.org/rfcb/3344

DOI : $10.4000 /$ rfcb.3344

ISSN : 2429-4373

Éditeur

CRECIB - Centre de recherche et d'études en civilisation britannique

\section{Édition imprimée}

Date de publication : 1 septembre 2004

ISBN : 2-911580-19-2

ISSN : 0248-9015

Référence électronique

Emmanuelle Avril, «Rajiv PRABHAKAR, Stakeholding and New Labour», Revue Française de Civilisation Britannique [En ligne], XIII-1 | 2004, mis en ligne le 01 septembre 2004, consulté le 24 septembre 2020. URL : http://journals.openedition.org/rfcb/3344 ; DOI : https://doi.org/10.4000/rfcb.3344

Ce document a été généré automatiquement le 24 septembre 2020.

\section{(c) $($ ) $(9)$}

Revue française de civilisation britannique est mis à disposition selon les termes de la licence Creative Commons Attribution - Pas d'Utilisation Commerciale - Pas de Modification 4.0 International. 


\title{
Rajiv PRABHAKAR, Stakeholding and New Labour
}

Basingstoke: Palgrave Macmillan, 2003

\author{
Emmanuelle Avril
}

\section{RÉFÉRENCE}

Rajiv PRABHAKAR, Stakeholding and New Labour, Basingstoke: Palgrave Macmillan, 2003, xii + 162p. ISBN 1-4039-0360-3.

1 Cet ouvrage d'économie politique écrit par un membre de la London School of Economics relance le débat autour de la notion de 'stakeholding' (ou théorie des parties prenantes), remise au goût du jour au milieu des années 1990 par l'ouvrage de Will Hutton, The State We're In. Immédiatement reprise à son compte par Tony Blair, l'expression fut rapidement écartée du discours officiel des porte-parole du gouvernement à la suite des railleries des adversaires politiques du New Labour de gauche comme de droite. L'auteur entend démontrer que si le terme controversé de 'stakeholding' a bien disparu de la terminologie officielle, il demeure néanmoins la pierre angulaire du projet des réformistes travaillistes dans les domaines du gouvernement d'entreprise et de la politique sociale. L'ouvrage se veut donc une défense et illustration d'un concept injustement décrié: loin de n'être qu'un slogan vide de substance, la notion de 'stakeholding' désigne une théorie cohérente et réellement novatrice, qui se distingue, bien qu'en leur empruntant, de la démocratie sociale keynésienne et du libéralisme économique. L'auteur s'intéresse en outre à la mise en pratique du projet par le gouvernement New Labour afin d'en démontrer la viabilité.

2 L'ouvrage se divise en sept chapitres. Après un premier chapitre introductif retraçant l'émergence d'un nouveau projet ayant permis au centre-gauche de se renouveler, les chapitres deux à cinq présentent les termes du débat. L'auteur commence par distinguer deux modèles et en analyse les fondements intellectuels: le modèle collectiviste d'abord, proche du keynésianisme sans y être réduit, et le modèle 
individualiste ensuite, inspiré du libéralisme économique (chapitres deux et trois). Il montre ensuite comment les deux modèles peuvent être conciliés: le concept de 'stakeholding' permet en effet d'associer le marché et la société civile (chapitre quatre). Dans le cinquième chapitre l'auteur présente une réponse systématique aux critiques, soulignant la spécificité et la cohérence du projet qu'il défend. Le chapitre six, dont le titre reprend celui de l'ouvrage, tente de mettre le concept de 'stakeholding' à l'épreuve des faits et en souligne la pertinence dans une définition du projet politique de New Labour. L'auteur s'intéresse en particulier à la Company Law Review et aux réformes sociales telles que 'welfare-to-work', les retraites, et les "Invididual Learning Accounts". Dans le dernier chapitre l'auteur conclut que la notion de 'stakeholder' constitue bien un élément moteur du renouveau programmatique du centre-gauche dans les années 1990, renouveau rendu indispensable par la mondialisation des échanges et par l'incapacité du parti travailliste traditionnel à revenir au pouvoir. Le terme de 'stakeholding' n'est donc pas selon lui un slogan creux mais une véritable philosophie politique.

3 Le débat philosophique présenté dans cet ouvrage est stimulant bien que parfois un peu mécanique dans sa présentation. Soucieux d'anticiper les critiques, l'auteur multiplie les précautions rhétoriques, ce qui ralentit le rythme d'une argumentation souvent répétitive. Cette extrême prudence tient en grande partie au fait que l'auteur se propose de concilier des théories traditionnellement antagonistes, et de les dépasser sans les renier. Un tel parti pris ne peut que lui attirer les foudres des critiques de gauche comme de droite pour qui une telle approche s'apparente à un compromis dénaturant l'un comme l'autre modèle. Il reste que l'auteur présente un tableau exhaustif de la littérature existante sur le sujet, très précieuse pour le lecteur qui souhaiterait poursuivre les recherches sur cette question.

4 En revanche, l'analyse de la mise en pratique des préceptes développés dans les cinq premiers chapitres laisse sur sa faim le lecteur qui, alléché par la promesse d'un titre laissant attendre une analyse détaillée de la politique de New Labour depuis 1997, découvre que seul le sixième chapitre (36 pages sur 162) s'attaque véritablement à ce volet. De plus, le tableau proposé de la mise en pratique du projet 'stakeholding' est, de l'aveu même de l'auteur, très sélectif : la réforme du gouvernement d'entreprise est considérée sous l'angle exclusif des délibérations de la Company Law Review et l'analyse des réformes sociales fait l'impasse sur la réforme du système de santé.

L'auteur a en outre quelque peine à nous faire croire que le gouvernement travailliste a véritablement la volonté et le pouvoir d'imposer le nouveau modèle de gouvernance au moment où l'exigence pour les entreprises d'évaluer l'impact social et environnemental de leur activité dans leur rapport annuel vient d'être abandonnée. La vision qui nous est proposée des relations entre le gouvernement et le monde des affaires paraît donc bien utopiste si la mise en place des réformes doit dépendre de la seule bonne volonté des entreprises d'exercer leur responsabilité sociétale, sans mise en place d'un cadre légal comprenant des sanctions en cas de non-conformité. En ce qui concerne la politique sociale, l'auteur défend le principe d'une approche dite « de bas en haut» ( 'bottom-up'), fondée sur des institutions collectives non étatiques, jugée supérieure à l'approche traditionnelle dite « de haut en bas " ('top-down') émanant d'un État central. S'il est vrai que l'on trouve quelques exemples de succès (comme les Credit Unions, quoiqu'il s'agisse là d'un développement associé au mouvement coopératif plutôt qu'au gouvernement travailliste), le bilan est très mitigé au regard des nombreux échecs (comme l'abandon précipité des Individual Learning Accounts évoqué par l'auteur, qui 
refuse pourtant de considérer cet abandon comme une faillite). L'idée chère à New Labour d'un État qui favoriserait le changement sans l'imposer se défend mieux en théorie qu'en pratique. On peut souligner que cet État qui se refuse à faire pression sur les entreprises pour les obliger à appliquer les réformes sait par ailleurs faire preuve d'une très grande fermeté lorsqu'il s'agit de sanctionner les éléments moins coopératifs de la société civile pour qui la contribution au système est considérée comme un devoir autant qu'un droit.

Enfin, l'auteur, désireux de souligner le caractère novateur du concept de 'stakeholding', semble vouloir situer l'année zéro du débat en 1996 avec la publication de l'ouvrage de Will Hutton et le discours de Singapour de Tony Blair. Ce concept, né aux États-Unis dans les années soixante et systématisé par Richard Freeman dès 1984, ne peut pourtant guère être considéré comme une innovation des modernisateurs travaillistes. Quant à la responsabilité sociétale, c'est là une idée que le monde de l'entreprise a reprise à son compte dès les années 1980 sous la pression d'ONG telles que Greenpeace et Amnesty International, les gouvernements y étant à l'époque farouchement hostiles.

7 Ces réserves soulignent en creux l'intérêt majeur de l'ouvrage qui est de rouvrir le débat sur la nature du projet politique de New Labour en le libérant du boulet de la «troisième voie» théorisée par Giddens. L'expression est d'ailleurs critiquée par l'auteur qui indique qu'elle a été source de malentendus et a desservi le projet qu'elle entendait ériger en modèle. En plaçant ce débat fermement sur le terrain de la philosophie politique, l'ouvrage permet d'aller au-delà de la conception communément admise de New Labour comme simple machine à communiquer, véhicule de l'opportunisme acharné de ses dirigeants. S'il est vrai que le fonctionnement du gouvernement de Tony Blair ne peut se comprendre sans considérer les aspects de présentation et de communication, il n'en reste pas moins que s'intéresser à la substance de New Labour et donc à sa dimension idéologique ouvre une réflexion fructueuse sur l'impact de la mondialisation, le rôle de l'État et des marchés, et la place de l'individu dans la société.

\section{AUTEURS}

\section{EMMANUELLE AVRIL}

Université de la Sorbonne Nouvelle-Paris III 